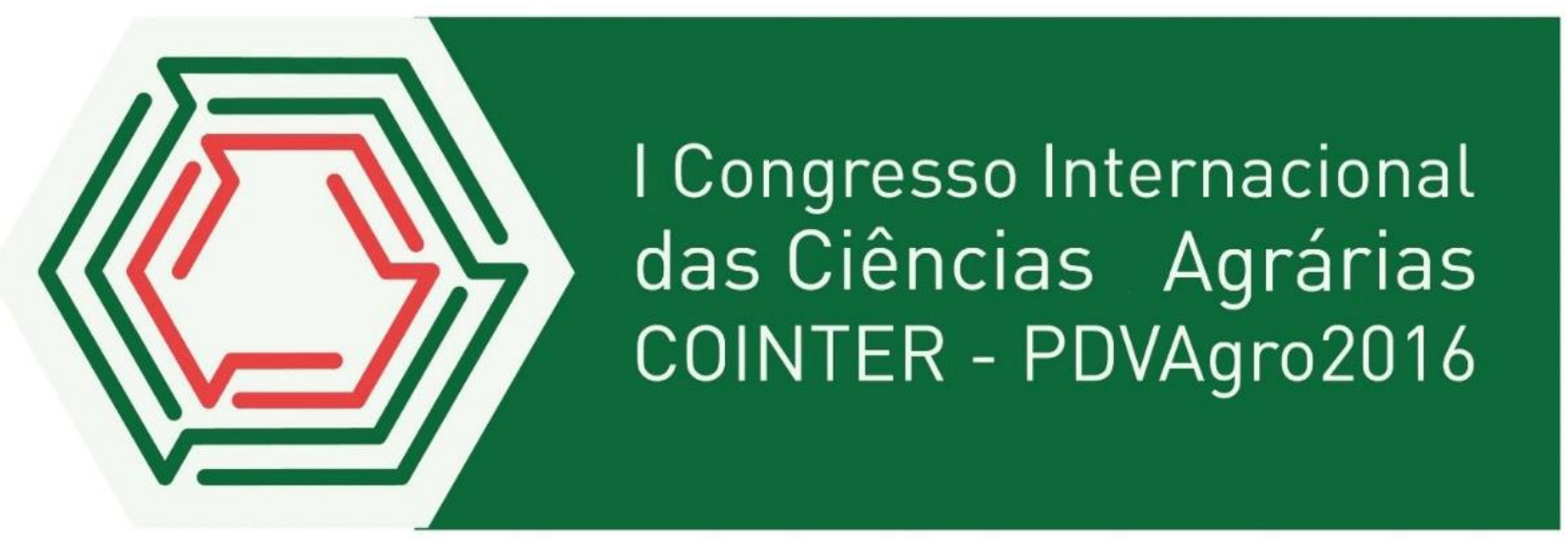

\title{
FITORREMEDIAÇÃO NA RECUPERAÇÃO DE ÁREAS DEGRADADAS E COMBATE À DESERTIFICAÇÃO: ESTADO DA ARTE
}

Apresentação: Comunicação Oral

\begin{abstract}
Julineide Gadelha Silvestre Coêlho ${ }^{1}$; Jordania Araújoㅜ; Anny Kelly Vasconcelos de Oliveira Lima²; Frederico Campos Pereira ${ }^{3}$
\end{abstract}

\section{Resumo}

Atualmente pode ser observado em amplos setores da sociedade um grande interesse nos crescentes dados relacionados aos poluentes encontrados no meio ambiente, além da atmosfera, o solo vem recebendo grandes quantidades de poluentes, assim provocando degradação e acumulação de compostos químicos maléficos a saúde, tanto do solo como a humana. Por esses motivos aumenta o interesse por técnicas que minimizem os efeitos negativos no solo, a fitorremediação é uma técnica estudada que possui um lugar de destaque devido à sua eficiência na descontaminação e recuperação dos solos e também devido ao seu custo ser mais acessível do que outras técnicas. A presente revisão bibliográfica foi realizada através da análise do material disponível nos bancos de dados e engloba diversos trabalhos que têm sido desenvolvidos na área de remediação de poluentes do ambiente. Em vista disso, é necessário que mais estudos nessa área sejam realizados para melhor conhecermos a capacidade fitorremediadora das plantas para a sua possível utilização no combate à degradação dos solos e ao processo de desertificação.

Palavras-chave: Poluentes, Degradação, solos e recuperação.

\section{Introdução}

O intenso aumento da população mundial gera uma busca cada vez maior de alimentos, espaço e condições para sobrevivência, fazendo com que as ações antrópicas ao meio ambiente sejam, ao longo do tempo, cada vez maiores (ALVES, 2006).

As atividades antrópicas voltadas para a mineração, indústria metalúrgica, indústrias químicas, agricultura, dentre outras, têm causado distúrbios na biosfera, ao liberar rejeitos orgânicos como hidrocarbonetos, inorgânicos e os metais pesados presentes em grande parte dos rejeitos industriais (Bhargava, Carmona, Bhargava \& Srivastava, 2012).

\footnotetext{
${ }^{1}$ Mestrado em Tecnologia Agroalimentar, UFPB Campus Bananeiras, E-mail: julineidegadelha@gmail.com

${ }^{2}$ Dra. Pesquisadora FAPESQ, IFPB, Picuí-PB, E-mail: annykellyv@hotmail.com

${ }^{3}$ Dr. Professor Agroecologia, IFPB, Picuí-PB, E-mail: fredcampos2000@yahoo.com
} 
Nesse modelo agrícola, o uso de adubos industriais, herbicidas e inseticidas tem poluído o ambiente, além de contaminar os alimentos com substâncias tóxicas. A monocultura, adotada nesse modelo, além de ser dependente de constantes intervenções geradoras de poluição e erosão do solo, provoca a redução da biodiversidade local e em muitos casos comprometem o patrimônio genético da agricultura.

Em termos gerais, qualquer alteração causada pelo Homem no ambiente gera, em última análise, algum tipo de degradação ambiental. O Guia de Recuperação de Áreas Degradadas, publicado pela SABESP, (2003, p. 4) define degradação ambiental, como sendo "as modificações impostas pela sociedade aos ecossistemas naturais, alterando (degradando) as suas características físicas, químicas e biológicas, comprometendo, assim, a qualidade de vida dos seres humanos".

Uma série de descobertas científicas combinada à pesquisa interdisciplinar vem desenvolvendo alternativas promissoras para a remediação do solo, as quais são menos agressivas ao ambiente (ecologicamente corretas) e economicamente mais viáveis (HAQUE, PERALTAVIDEA, JONES, GILL \& GARDEA-TORRESDEY, 2008).

Nesse contexto, aumenta o interesse pela utilização da biorremediação, caracterizada como uma técnica que objetiva descontaminar solo e água por meio da utilização de organismos vivos, como microrganismos e plantas (PIRES et al., 2003ab). Dentro da biorremediação, a fitorremediação é uma das técnicas mais estudadas. Segundo PIRES et al. (2003ab), esta técnica envolve o emprego de plantas, sua microbiota associada e de amenizantes (corretivos, fertilizante, matéria orgânica etc.) do solo, além de práticas Agronômicas que, se aplicadas em conjunto, removem, imobilizam ou tornam os contaminantes inofensivos para o ecossistema.

A recuperação de áreas degradadas tem por objetivo fornecer ao ambiente degradado, condições favoráveis a reestruturação da vida num ambiente que não tem condições de se regenerar por si só. Através de obras no terreno como a construção de terraços, banquetas, etc., ou ainda, da implantação de espécies vegetais, podemos conduzir a recuperação de uma área degradada.

O procedimento para remediação e consequente recuperação dessas áreas é lento e está relacionado à capacidade de restabelecimento do solo, onde se recompõem as características químicas, físicas e biológicas a um nível mínimo, que permita o de $\neg$ senvolvimento de espécies vegetais e da atividade microbiana, tão importante para o estabelecimento e sucessão da macrobiota (MENDES FILHO, 2010).

O presente trabalho tem por objetivo elencar os principais métodos e apresentar a fitorremediação como solução para a descontaminação e recuperação de solos degradados, evidenciando seus tipos e caracterizando o local contaminado para um melhor aproveitamento da técnica. 


\section{METODOLOGIA}

Este estudo constitui-se de uma revisão da literatura especializada, realizada entre maio de 2016 e agosto de 2016, no qual se realizou uma consulta a livros e periódicos presentes no banco de dados da Biblioteca da Universidade Federal da Paraíba (UFPB) e por artigos científicos selecionados através de busca no banco de dados do Scielo, periódico Capes e Google acadêmico.

Os critérios de inclusão para os estudos encontrados foram à abordagem do processo de recuperação de áreas degradas através da utilização da fitorremediação, e estudos comparativos entre os modelos existentes. Logo em seguida, buscou- se estudar e compreender os principais resultados encontrados e a forma de aplicação empregada nesses estudos, de modo, a encontrar os mecanismos e aplicações, bem como as vantagens e desvantagens da técnica de fitorremediação, aplicada in situ, com isso uma possível conclusão satisfatória sobre a fitorremediação.

\section{RESULTADOS E DISCUSSÃO}

\section{Áreas degradadas}

O surgimento de áreas degradadas, no Brasil, tem aumentado consideravelmente ao longo dos anos, ocasionando inúmeros prejuízos ao meio ambiente. Segundo a FAO (2005), aproximadamente $16 \%$ da área total do Brasil apresenta algum estado de degradação do solo induzida por atividades antrópicas. Em ambientes urbanos, a acelerada urbanização, a falta de planejamento e as inadequadas técnicas de manejo do solo são fatores que incrementam essa degradação e promovem a perda de solos férteis e sua progressiva desertificação.

A desertificação é um problema de grandeza mundial que atinge zonas áridas, semiáridas e subúmidas (ONU, 1992). Caracteriza-se por apresentar perda de produtividade dos solos, decorrente de desmatamento e erosão, tendo como consequência o declínio econômico de áreas e prejuízo aos agricultores familiares. No Brasil, a maior gravidade é identificada nos Núcleos de Desertificação ocorrentes no Semiárido, que são regiões caracterizadas por apresentarem baixa precipitação anual, alta evapotranspiração, e bolsões de pobreza (MMA, 2004).

Silva et al. (2010), observa que as altas incidências de raios solares com consequentes altas de temperaturas, aumentam os índices de evapotranspiração, variabilidade climática, assim como os períodos de seca, a intensidade das chuvas, a erodibilidade dos solos, o escoamento superficial e a derivação antropogênica, como o desmatamento indiscriminado, as queimadas e o pastoreio da ovinocaprinocultura acima da capacidade de suporte do ambiente, foram os fatores que aceleraram e 
agravaram o processo de desertificação em áreas com essa propensão e também na região do município de Picuí.

Com o objetivo de mitigar esses impactos ambientais e minimizar os riscos inerentes à instabilidade de taludes, a fitorremediação tem surgido como uma técnica eficiente e de baixo custo, sendo uma alternativa aos métodos tradicionais de estabilização e reforço de solos. A vegetação tem sido reconhecida não só por suas qualidades estéticas, mas também por seus efeitos hidromecânicos benéficos e pela proteção do solo contra a erosão. Além disso, a vegetação afeta a estabilidade superficial do solo, principalmente pelo aumento na resistência ao cisalhamento, através do reforço oferecido pelas raízes (GRAY \& SOTIR, 1996).

Determinadas plantas podem, por meio do processo de fitorremediação, absorver os pesticidas do solo, ou também promover um processo chamado fitoestimulação, no qual há liberação de exsudatos e enzimas que incrementam as transformações bioquímicas e/ou a mineralização em virtude da atividade microbiana e de fungos micorrízicos na rizosfera (WILSON; TISDELL, 2001).

\section{Fitorremediação}

Uma das técnicas mais estudadas e que mais se destaca dentro da biorremediação in situ é a fitorremediação (COUTINHO; BARBOSA, 2007). Muito utilizada atualmente em sistemas de saneamento de água e recuperação de solos contaminados pela agricultura, conhecida desde 1991, como uma técnica que utiliza plantas que apresentem potencial para degradar, extrair, conter ou imobilizar os contaminantes do solo e da água, se tornando inócuo ao ambiente (VASCONCELLOS; PAGLIUSO; SOTOMAIOR, 2012).

A facilidade/resistência que certas plantas possuem de capturar ou simplesmente neutralizar a ação de determinados compostos tóxicos aos solos e/ou água, servindo como verdadeiros filtros “verdes" (PILON-SMITS, 2005). Grande parte dos conhecimentos sobre fitorremediação que hoje conhecemos, provém de estudos realizados em diversas áreas, sendo que desta forma, aos poucos foi se verificando a eficiência das plantas na remoção de metais pesados e outros contaminantes.

Esta biotecnologia vem sendo utilizada há anos em vários países e, em certos casos, apresenta menor custo e maior eficiência na remoção dos contaminantes do que as técnicas físicas e químicas, sendo atualmente utilizada em escala comercial no tratamento de diversos resíduos e na remediação de áreas degradadas (BAMFORTH; SINGLETON, 2005). 
Este é um método autossustentável e fisicamente favorável a remediação de áreas com níveis de contaminação de moderado a baixo e pode ser usado em associação com outros métodos mais tradicionais ou como última etapa de um processo de descontaminação (GRATÃO, 2005).

A fitorremediação é compreendida por cinco mecanismos (Tabela 1), considerados diretos, que se dividem em fitoextração, fitotransformação e fitovolatilização, e por mecanismos indiretos como fitoestabilização e fitoestimulação (TAVARES, 2009).

Tabela 1 - Mecanismos diretos e indiretos

\section{MECANISMOS DIRETOS}

FITOEXTRAÇÃO - O contaminante é absorvido no tecido vegetal e subsequentemente são volatizados.

FITOTRANSFORMAÇÃO - O contaminante sofre bioconversão no interior das plantas ou em sua superfície, passando a formas menos inócuas.

FITOVOLATIZAÇÃO - O contaminante é absorvido e convertido em forma volátil, que é liberada na atmosfera.

\section{MECANISMOS INDIRETOS}

FITOESTABILIZAÇÃO - O contaminante é imobilizado por meio de sua lignificação ou humificação.

FITOESTIMULAÇÃO - Estimula a planta para a biodegradação microbiana dos contaminantes, mediante exsudatos radiculares e/ou fornecimento de tecidos vegetais.

Essa técnica, que no Brasil é ainda incipiente, tem uso difundido nos EUA e na Europa, principalmente na remediação de metais pesados e têm sido identificadas algumas espécies de comprovada eficiência (SANTOS et al., 2004).

A ocorrência de áreas degradadas torna-se cada vez mais frequente e preocupante. A fitorremediação é uma alternativa capaz de empregar sistemas vegetais fotossintetizantes e sua microbiota com o fim de desintoxicar ambientes degradados ou poluídos. É uma tecnologia barata, com capacidade de atender uma maior demanda, e que apresenta o maior potencial de desenvolvimento futuro (CHEKOL, 2004). O método de fitorremediação oferece várias vantagens; grandes áreas podem ser tratadas de diversas maneiras, a baixo custo, com possibilidades de remediar, o solo e subsolo contaminados e ao mesmo tempo embelezar o ambiente. Entretanto, o tempo para se obter resultados satisfatórios pode ser longo (DINARDI, 2003). 
A destruição das coberturas vegetais em áreas contaminadas por elementos de alta toxidade agrava a degradação do solo, promovendo assim: erosão hídrica e eólica, lixiviação dos contaminantes para o lençol freático, desencadeando progressivo grau de contaminação de outras áreas. A recuperação desses ambientes necessita estudos de diversas naturezas sobre solo, vegetação e água (CUNNINGHAM et al, 1996). E em se tratando de revegetação, a identificação de espécies tolerantes ou com capacidade de acumular os contaminantes mostra-se fundamental para o sucesso do processo.

Em razão disto, é crescente o número de pesquisas envolvendo a fitorremediação. Todavia, tais estudos são ainda incipientes e requerem muitas experimentações sob condições edafoclimáticas tropicais, para identificação de espécies capazes de atuar em programas de fitorremediação, à semelhança do que já é realizado na Europa, EUA, Nova Zelândia e Austrália (PIRES et al. 2009).

\section{CONCLUSÃO}

A fitorremediação é uma técnica que surge do avanço da biotecnologia para a recuperação de solos que estão sofrendo degradação por esse recurso não renovável. É um meio promissor por ainda estar em desenvolvimento, podendo ser constantemente melhorado. $\mathrm{O}$ solo pode ser remediado por várias maneiras que constituem os tipos da fitorremediação. Atualmente as técnicas in situ são priorizadas por não agredir tanto o meio ambiente. O baixo custo é um fator pelo qual esse tipo de descontaminação é preferencialmente escolhido, além de que pode ser aplicado em grandes áreas e dispor de facilidade de aplicação.

Apesar de promissora, a técnica apresenta limitações, uma vez que os resultados podem ser obsevados em longo prazo, pelo fator de adaptação das plantas, sendo essa a principal desvantagem. Além de que a contaminação pode entrar na cadeia alimentar, prejudicando diretamente os organismos inerentes ao meio ambiente.

Tais limitações não impedem a técnica de ser considerada uma ótima solução para a recuperação de solos degradados por hidrocarbonetos de petróleo, que uma vez melhorada, pode vir a se tornar um sistema ideal.

\section{REFERÊNCIAS}


ALVES, M.C. Recuperação dos solos degradados pela agricultura. In: ENCONTRO NACIONAL SOBRE EDUᄀCAÇÃO AMBIENTAL NA AGRICULTURA, 5., 2006, Campinas. Anais. Campinas: Instituto Agronômico, 2006. 1-CD-ROM;

BAMFORTH, S.; SINGLETON, I. Bioremediation of polycyclic aromatic hydrocarbons: current knowledge and future directions. Journal of Chemical Technology and Biotechnology, v.80, n.7, p.723-736, 2005;

BHARGAVA, A., CARMONA, F. F, BHARGAVA, M., \& SRIVASTAVA, S. (2012). Approaches for enhanced phytoextraction of heavy metals. Journal of Environmental Management, 105, 103120. doi:10.1016/j.jenvman.2012.04.002.

CHEKOL, T.; VOUGH, L. R. \& CHANEY, R. L. (2004) - Phytoremediation of polychlorinated biphenylcontaminated soils: the rhizosphere effect. Environment International, v. 30, n. 6, p. 799804;

CUNnINGHAM, S. D.; ANDERSON, T. A.; SCHWAB, A. P. Phytoremediation of soils contaminated with organic pollutants. Adv. Agron., v. 56, p. 55-114,1996;

DINARDI, Ana Lígia et al. Fitorremediação: III Fórum de Estudos Contábeis, Faculdades Integradas Claretianas. Anais. Rio Claro, São Paulo, 2003;

FAO - LAND AND WATER DEVELOPMENT DIVISION. National soil degradation maps, 2005. Disponível em: < http://www.fao.org/landandwater/agll/glasod/glasodmaps.jsp?country=BRA\& search=Display+map+\%21 >. Acesso em: 15 de julho de 2016.

GRAY, D.H.; SOTIR R.B. Biotechnical and soil bioengineering slope stabilization: a practical guide for erosion control. Canada: John Wiley \& Sons, Inc, 1996. 378 p.

HAQUE, N., PERALTA-VIDEA, J. R., JONES, G. L., GILL, T. E., \& GARDEA- TORRESDEY, J. L. (2008). Screening the phytoremedia $\neg$ tion potencial of desert broom (Braccharis sorothroides Gray) growing on mine tailings in Arizona, USA. Environmental Pollution, 153, 362-368. doi:10.1016/j. envpol.2007.08.024. 
MENDES FILHO, P.F.; VASCONCELLOS, R.L.F.; PAULA, A.M.; CARDOSO, E.J.B.N. Evaluating the po-tential of forest species under microbial management of the restoration of degraded mining areas. Water, Air and Soil Pollution, v.208, n.1/4, p.79-89, 2010.

MMA. Ministério do Meio Ambiente. Programa de ação nacional de combate

PIRES, F. R. et al. Fitorremediação de solos contaminados com tebuthiuron utilizando-se espécies cultivadas para adubação verde. Planta Daninha, Viçosa, v. 23, n. 4, p. 711-717, 2005b.

ONU. Agenda 21 - Capítulo 12: Manejo de Ecossistemas Frágeis: A Luta contra a Desertificação e a Seca. In: CNUMAD: Conferência das Nações Unidas sobre o Meio-Ambiente e Desenvolvimento. Rio de Janeiro, 1992.

SILVA, I. A. de SOUSA; SILVA, J. C. B. da; SILVA, K. A e. Estudo da desertificação em Gilbués

- Piauí: Caracterização física, variabilidade climática e impactos ambientais. I SIREGEO, Simpósio Regional de Geografia do Cerrado, Barreiras, BA. p. 331-343, 2010.

PIRES, F. R. et al. Inferências sobre atividade rizosférica de espécies com potencial para fitorremediação do herbicida tebuthiuron. Revista Brasileira de Ciência do Solo, Viçosa, v. 29, n. 4, p. 627-634, 2005a.

PIRES, F. R.; EGREJA FILHO, F. B.; PROCÓPIO, S. O. Inferências sobre mineralogia dos solos, sorção e fitorremediação de herbicidas. In: FERREIRA, A. et al. (Orgs.). Tópicos especiais em produção vegetal I. Vitória: Edufes, 2009. p. 391-406asileira de Física, 2005. v. 1. p. 175-175, 